\title{
CELLULOSE AS A NANOSTRUCTURED POLYMER: A SHORT REVIEW
}

\author{
Michael Ioelovich* \\ Cellulose has a complex, multi-level supermolecular architecture. This \\ natural polymer is built from superfine fibrils having diameters in the \\ nano scale, and each such nanofibril contains ordered nanocrystallites \\ and low-ordered nano-domains. In this review, the nano-structure of \\ cellulose and its influence on various properties of the polymer is \\ discussed. In particular, the ability of nano-scale crystallites to undergo \\ lateral co-crystallization and aggregation, as well as to undergo phase \\ transformation through dissolution, alkalization, and chemical modifica- \\ tion of cellulose has been the subject of investigation. The recent \\ investigations pave the way for development of highly reactive cellulosic \\ materials. Methods for preparation nanofibrillated cellulose and free \\ nano-particles are described. Some application areas of the nanostruc- \\ tured and nano-cellulose are discussed.
}

Keywords: Cellulose; Nanostructure; Nanofibrils; Nanoparticles; Properties; Applications

Contact information: Polymate Ltd, P.O.Box 73, Migdal HaEmek 23100, Israel;

*Corresponding author: bd895892@zahav.net.il

\section{INTRODUCTION}

Various properties of sufficiently large crystalline phases having sizes in the range of hundreds of microns, such as specific weight, parameters of crystalline unit cell, melting points, solubility, and others, can be considered as constants of a given sample. However, with decreasing size of the phase down to the nano-scale, the laws of the classic thermodynamics are no longer applicable, due to significant contribution of the specific surface $(\mathrm{S})$ to the thermodynamic functions. In this case, behaviors of nano-phase matters obey the thermodynamic and physico-chemical laws for transformations of small phases (Frolov 1982).

The eminent representative of nanostructured matter is natural cellulose. This renewable natural polymer is present in all plants and algae; cellulose of the tunicin type forms a shell of certain marine creatures, and it is also synthesized by some microorganisms (Klemm et al. 2005). The main sources of cellulose are plants. The content of cellulose in bushes is about $30 \%$, in woods $40-50 \%$, in bast plants (flax, ramie, etc.) $65-70 \%$, and in cotton fibers upwards of $90 \%$. The annual biomass production of cellulose in nature is about 1 trillion tons, making it a virtually inexhaustible source of raw materials. As is known, cellulose has a complex, multi-level architecture (Ioelovich 1999). This natural polymer is built from bundles of superfine fibrils having diameters in the nano scale, and each such nanofibril is composed to a large part (60-80\%) by ordered crystallites and to a lesser part by disordered (mesomorphous and amorphous) domains. 
An individual cellulose chain passes through numerous crystallites and disordered domains and binds them together with 1,4- $\beta$-glycoside bonds. Since cellulose of various origins contains nano-scale fibrillar bundles, nanofibrils, nanocrystallites, and disordered nano-domains, this natural polymer can be defined as being nanostructured. To describe various behaviors of this nanostructured polymer, the dependence of its characteristics on specific surface area $(S \sim 1 / L)$, or lateral size $(L)$ of its nano-constituent has been taken into consideration.

In this review the nano-structure of cellulose and its influence on various properties of cellulose materials is discussed. Some application areas of the natural nanostructured polymer and isolated nano-particles are described.

\section{STRUCTURAL ORGANIZATION OF CELLULOSE}

Cellulose is a linear, stereo-regular polysaccharide built from repeated D-glucopyranose units linked by $1,4-\beta$ glycoside bonds. The lateral size of the cellulose chains is about $0.3 \mathrm{~nm}$. The degree of polymerization of native cellulose from various origins can fall in the range 1000 to 30,000 , which corresponds to chain lengths from 500 to 15000 $\mathrm{nm}$.

Cellulose is located within the fiber walls of plants. One fiber is an elongated vegetable cell. Fibers of various plants have different shapes and dimensions (Figs. 1-3). Fibers of cotton and bast plants are enough long, with lengths in the range of centimeters, while wood fibers are short, typically 1-3 mm in length (Katkevich and Milutina 1972; Usmanov and Razikov 1974). Cotton fibers are twisted, while fibers of wood - the tracheids - are generally untwisted and subject to flattening when delignified. Fibers of the bast plants (flax, ramie, etc.) are straight and round.

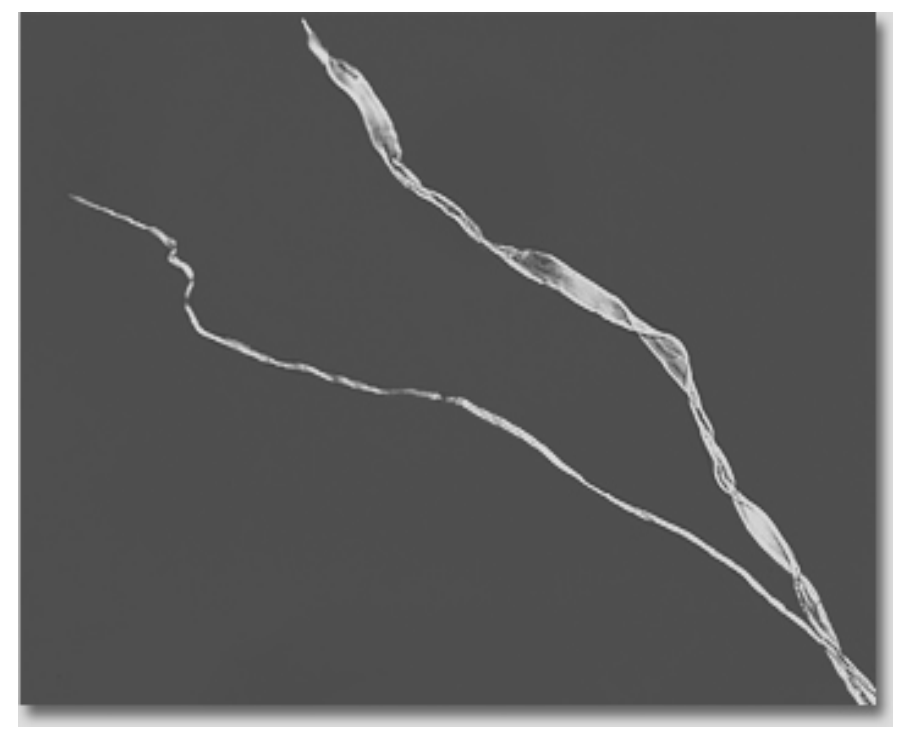

Figure 1. Microphotograph of twisted cotton fibers 


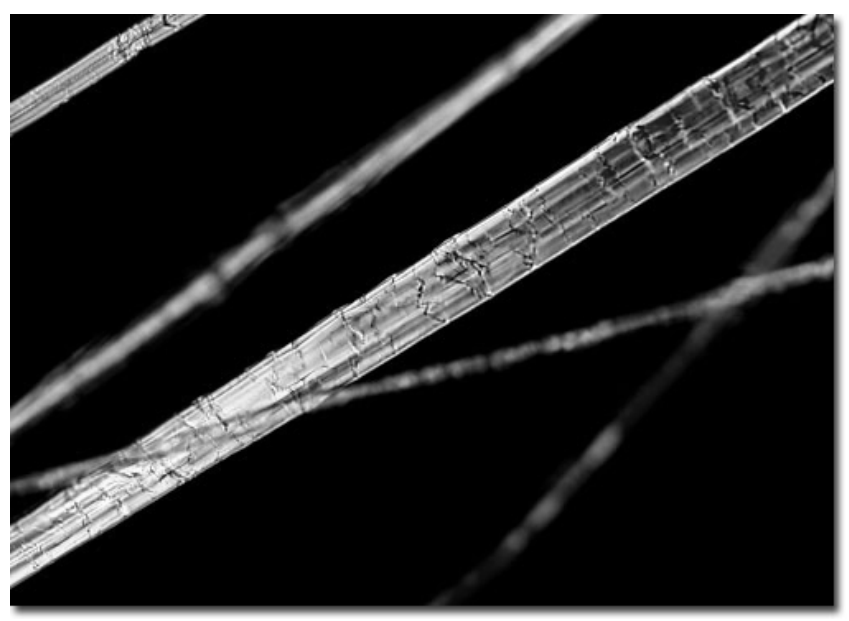

Figure 2. Straight fibers of rami

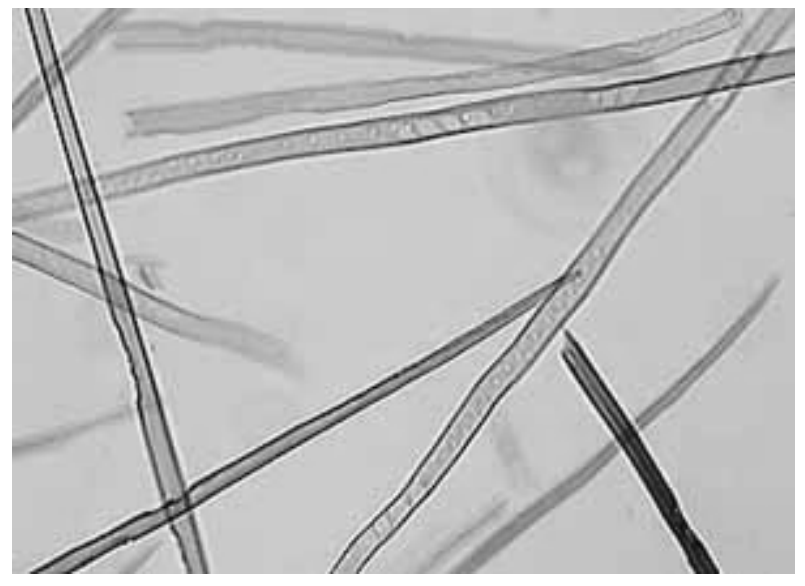

Figure 3. Tracheids of spruce wood

A hollow capillary called the lumen extends through most of the length of the fiber. Cellulose fibers contain various defects or dislocations: pores, cracks, nodes, compression failures, thin places, and other sites of damage (Ander et al. 2008). These dislocations are weak points for chemical attack and mechanical forces. The width of various plant fibers is $15-30 \mu \mathrm{m}$, including the lumen. The cell wall of the typical plant fiber has a thickness of 4-6 $\mu \mathrm{m}$ and consists of primary (P), secondary (S), and inside tertiary (T) walls. The primary and tertiary walls of fibers are thin, about $100 \mathrm{~nm}$. Nanofibrillar bundles of the P-and T-walls form disordered nets. The S-wall has a thickness of 3-5 $\mu \mathrm{m}$ and is composed of three layers, the S1, S2, and S3 layers. The dominant layer in the cell wall is the S2-layer, which by itself is typically $2-4 \mu \mathrm{m}$. The S2-layer contains nano-fibrillar bundles and lamellas located parallel to each other and orientated under an acute angle towards the fiber axis (Ioelovich and Ivulonok 1987; Ioelovich and Leykin 2008). This orientation imparts to cellulose fibers increased mechanical properties (Fig. 4). 


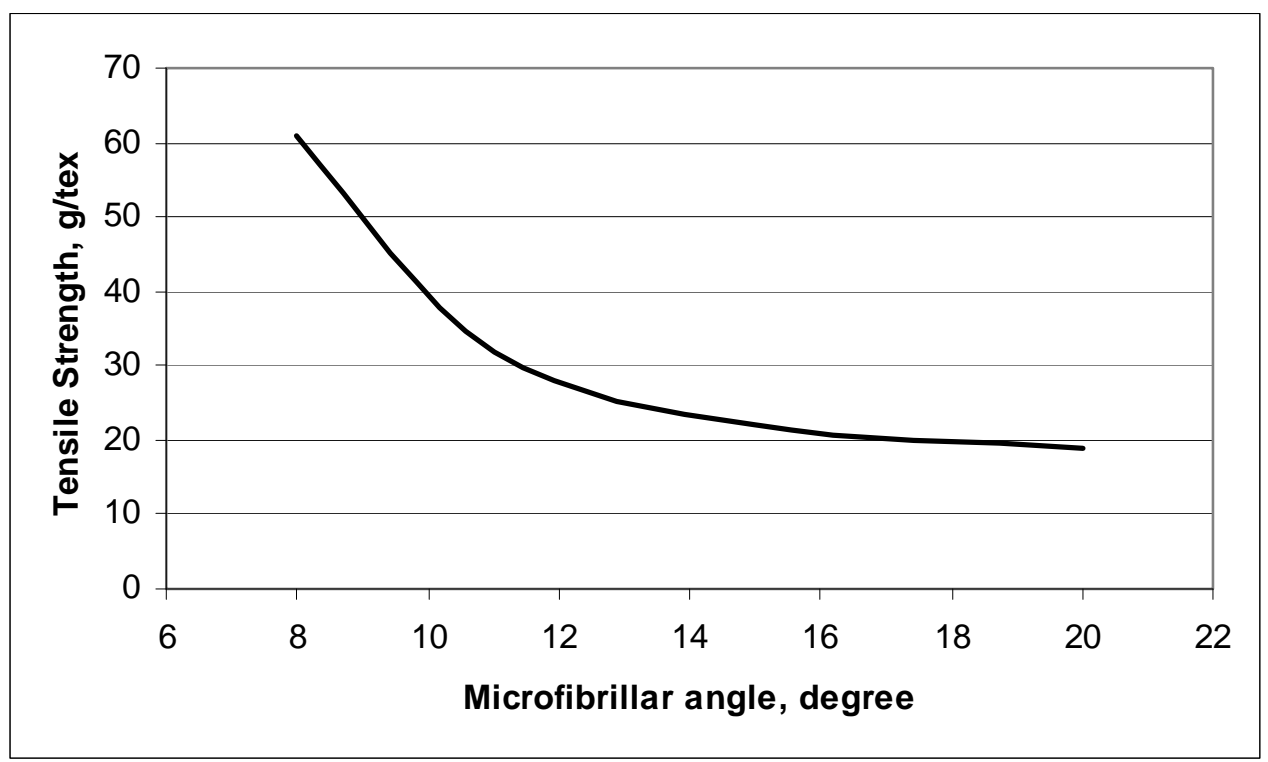

Figure 4. Dependence of tensile strength on microfibrillar angle towards the fiber axis in the S2layer of various natural fibers

The bundles and lamellas of the cell wall consist of elementary nanofibrils with lateral size 3-15 nm and length about $1 \mu \mathrm{m}$. Each such nanofibril contains ordered nanocrystallites and disordered nano-domains having about the same lateral sizes as elementary nanofibrils (Fig. 5). In cellulosic materials of various origins, the length of crystallites is in the range $50-150 \mathrm{~nm}$ and the disordered domains are $25-50 \mathrm{~nm}$.

In natural vegetable fibers the elementary nanofibrils and fibrillar bundles are separated by an amorphous ligno-hemicellulose matrix. Extraction of matrix components during cellulose isolation from natural fibers causes damage, often accompanied by removal of the external wall layers, obtaining pure cellulose having mainly the S2-layer. Moreover, the release of the fibril surface from the amorphous matrix permits direct contact of the elementary nanofibrils and formation of lateral fibrillar aggregates via cocrystallization of adjacent crystallites (Ioelovich et al. 1989; Ioelovich 1991).

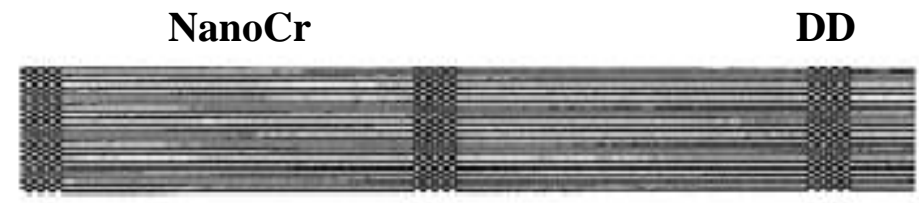

Figure 5. Elementary nanofibril of cellulose: $\mathrm{NanoCr}$ - nanocrystallite; DD-disordered domain

As a result of the lateral co-crystallization, the elementary fibrils lose their individuality and aggregate as secondary nanofibrils. The secondary nanofibrils of isolated cellulose can be agglomerated, with the formation of nanofibrillar bundles. These bundles can form bands or lamellas of cellulose. Various cellulose specimens, isolated 
from different plants and tunicin, have mainly the monoclinic $\mathrm{C}_{\beta}$ crystalline modification with space group P $2_{1}$ (Woodcock and Sarko 1980; Wada et al. 1993).

Apart from higher plants, cellulose of algae and celluloses produced by certain bacteria and fungi have specific structural organization. The bacteria Acetobacter xylinum synthesize primary nanofibrils with lateral size $7-13 \mathrm{~nm}$, which are aggregated to thin and flat bands having width of 70-150 nm (Fink et al. 1997; Klemm et al. 2006). Such bands can be in the form of a thin ribbon of $500 \mathrm{~nm}$ in width. The bacterial cellulose is highly swollen with water that fills gaps between the various structural elements. A peculiarity of bacterial and algae celluloses is that their crystallites have mainly the triclinic $\mathrm{C} 1 \alpha$ crystalline modification (Sarko and Muggli 1974; Preston 1975; Van der Hart and Atalla 1984; Salmon and Hudson 1997; Wada et al. 1993). Due to probably lower energy of hydrogen bonds, the $\mathrm{C} 1 \alpha$-form is metastable and can be converted into more stable $\mathrm{C} 1_{\beta}$ modification after thermo-chemical treatments (Sugiyama et al. 1991; Wada et al. 1993).

\section{NANOSTRUCTURE OF VARIOUS CELLULOSES}

The early models of cellulose structure postulated the presence in various cellulose samples of elementary fibrils having a constant lateral size of $3.5 \mathrm{~nm}$ (Manley 1965; Mülenthaler 1969). However, recent investigations don't confirm this conclusion. Just the opposite, detailed structural analyses have shown that lateral size of elementary nanofibrils in various celluloses is different (Nieduszynski and Preston 1970; Ioelovich 1991; Ioelovich 1992; Klemm et al. 2005). Selected results are shown in Table 1. As follows from these results, the lateral size of elementary nanofibrils varies in a wide range, from $3 \mathrm{~nm}$ for natural wood up to $15 \mathrm{~nm}$ for isolated algal cellulose. In isolated celluloses, the elementary nanofibrils can be aggregated in bundles with lateral size of 20-40 nm, and such bundles form lamellas, layers, or bands having thicknesses of about $100 \mathrm{~nm}$ (Katkevich and Milutina 1972; Klemm et al. 2005; Klemm et al. 2006; Ioelovich and Leykin 2006; Larsson 2007).

Table 1. Crystallinity and Lateral Size $(L)$ of Elementary Nanofibrils for Various Cellulose Samples*

\begin{tabular}{|c|c|c|}
\hline Sample & Crystallinity degree, $\%$ & $\mathrm{~L}, \mathrm{~nm}$ \\
\hline Natural soft-and hard wood & $60-62$ & $3-4$ \\
\hline Isolated sulfite cellulose & $62-63$ & $5-6$ \\
\hline Isolated Kraft cellulose & $64-65$ & $6-7$ \\
\hline Natural cotton & $68-69$ & $5-6$ \\
\hline Isolated cotton cellulose & $70-72$ & $7-8$ \\
\hline Natural flax or ramie & $65-66$ & $4-5$ \\
\hline Isolated flax or ramie cellulose & $67-68$ & $6-7$ \\
\hline Bacterial cellulose & $75-80$ & $7-8$ \\
\hline Cellulose of Valonia algae & $75-80$ & $10-15$ \\
\hline * (Ioelovich 1991; loelovich 1992).
\end{tabular}

The nano-architecture of the cellulose promotes isolation of nano-particles and nano-fibrils. Due to the presence in initial cellululose materials of the nano-scale constituents, it is possible to isolate these by relatively easy methods. In the most recent 
years, extensive investigations have been carried out regarding the preparation of the nanocellulose from cellulosic raw-materials. Various ways for making of nanocellulose have been proposed (see Hubbe et al. 2008). One way is to use a chemical treatment, mainly hydrolysis of cellulose, followed by mechanical disintegration or ultra-sound sonification (Favier et al. 1995; Cavaille et al. 2000; Lima and Borsali 2004; Azizi Samir at al. 2005; Ioelovich and Leykin 2006; Moran et al. 2008). The combination of acid hydrolysis and high-pressure disintegration permits isolation of free nano-crystalline particles having lengths of 100-200 nm and widths of 20-40 nm (Fig.6).

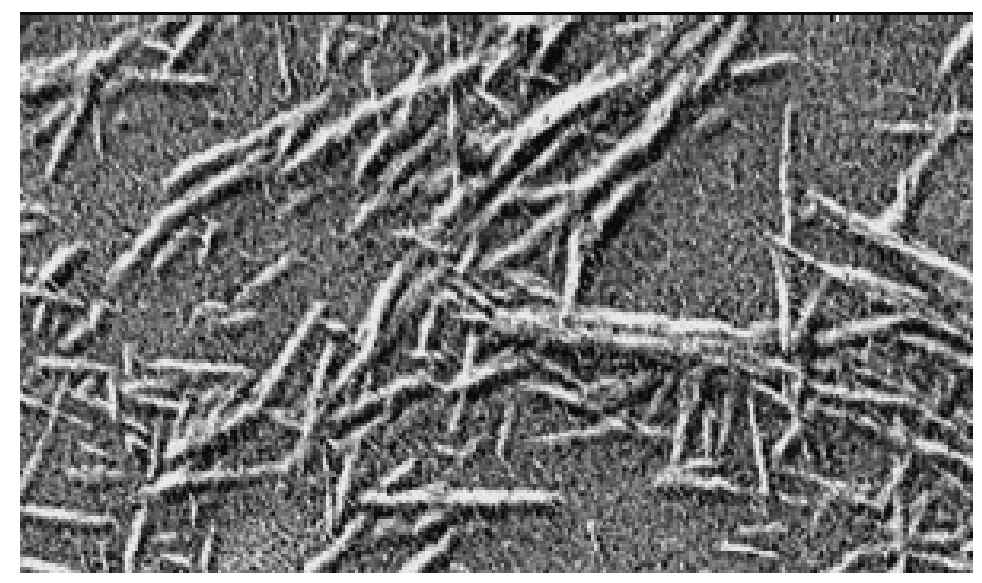

Figure 6. Nano-crystalline particles of cellulose

Dissolving methods (Ono et al. 2001; Li et al. 2001; Oksman et al. 2006) and cryo-crushing processes of hydrolyzed cellulose (Bhatnagar and Sain 2003; Bhatnagar and Sain 2005) have been described.

Repeated milling of the pulp in water over a long period of time permits complete fibrillation of the cellulose fibers and turn these into nano-fibrils (Nakagito et al. 2004; Chakraborty et al. 2005). The enzymatic pretreatment of cellulose fibers, followed by mechanical splitting in water by means of special high-shear mills or refiners, leads to the formation of nanofibrillated cellulose with average diameters of the nano-bundles about $100 \mathrm{~nm}$ and length $>1 \mu \mathrm{m}$ (Nakagaito and Yano 2004; Pakko et. al. 2007; Henriksson et al. 2007).

\section{Nanostructure and Distortion of Cellulose}

The surfaces of crystallites have paracrystalline distortions. For large crystals the volumetric portion of the surface layers of the crystals is neglible. However, with decrease of sizes, the contribution of surface layers and distortions to structure of the crystals increases, and for nano-crystallites these distortions become an essential influence (Ioelovich 1999). As a result, parameters of the unit cell of nanocrystallites and their specific volume are functions of crystallite size (Fig. 7).

\section{Aggregation Phenomena of Nanostructured Cellulose}

Nano-scale cellulose structures with highly developed specific surface (S) have an increased thermodynamic potential $(\mathrm{G})$, which is the cause of instability of nano-objects. 
According to thermodynamics, to achieve a more stable state, a nano-object or phase must decrease its specific surface:

$$
\Delta G=\sigma \Delta S<0
$$

where $\sigma$ is the specific surface energy.

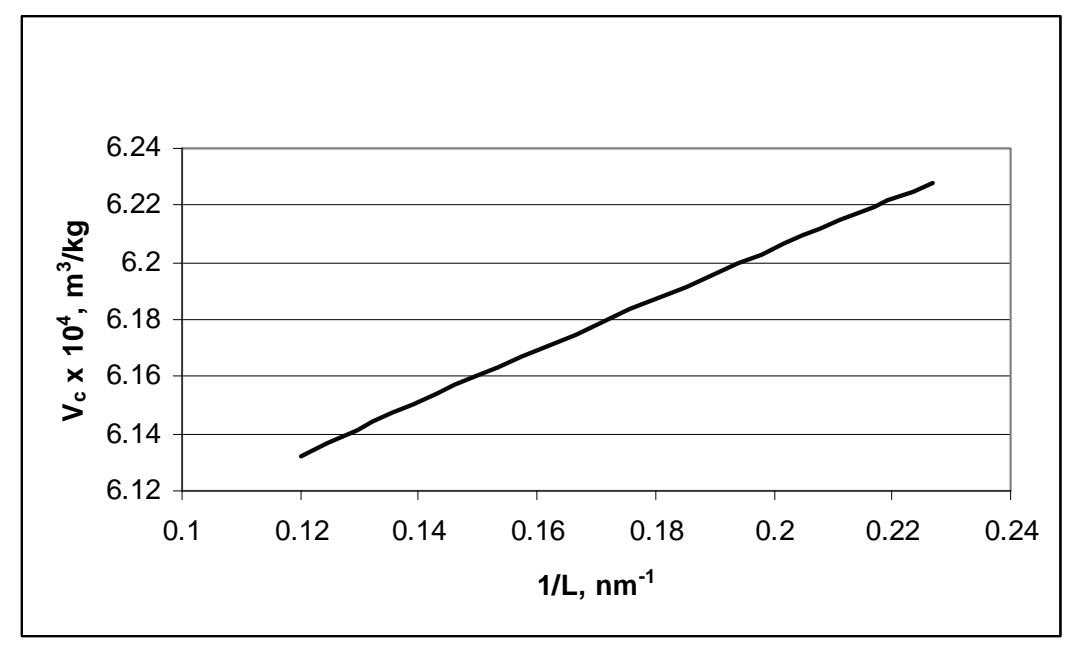

Figure 7. Dependence specific volume $\left(\mathrm{V}_{\mathrm{c}}\right)$ of $\mathrm{Cl}$ nanocrystallites on its lateral size $(\mathrm{L})$

Therefore, the nano-phase has an expressed tendency to form larger structures via aggregation and agglomeration. Concerning cellulose samples, the evident irreversible aggregation (lateral crystallization) of small nano-crystallites was discovered after cellulose isolation from wood by sulfite and particularly by Kraft cooking at increased temperatures (Table 2).

Table 2. Lateral size $(L)$ of Nano-Crystallites and their Aggregation Degree $(A)$ *

\begin{tabular}{|c|c|c|}
\hline Sample & $\mathrm{L}, \mathrm{nm}$ & $\mathrm{A}, \%$ \\
\hline Natural cellulose of spruce wood & $3.5(\mathrm{Lo})$ & 0 \\
\hline Cellulose isolated by organosolv cooking & 4.2 & 20 \\
\hline Cellulose isolated by sulfite cooking & 6.1 & 74 \\
\hline Cellulose isolated by Kraft cooking & 7.0 & 100 \\
\hline
\end{tabular}

*(Ioelovich 1991; loelovich 1999)

Another example of aggregation phenomenon is the formation of nano-crystalline particles with lateral size of $20-40 \mathrm{~nm}$ from small initial crystallites of cotton cellulose (L $=8 \mathrm{~nm}$ ) via an isolation process involving free nano-cellulose particles (Ioelovich and Leykin 2006). Expressed aggregation of elementary nanofibrils is apparent during biosynthesis of bacterial cellulose (BC). The elementary nanofibrils of $\mathrm{BC}$ having lateral size in the range 7-13 nm aggregate into thin and flat bands having widths of 70 to 150 $\mathrm{nm}$, while such bands form agglomerates of $500 \mathrm{~nm}$ in width (Fink et al. 1997; Klemm et al. 2006). 
Hence, the presence in cellulose samples of such diverse structures as nanofibrillar bundles, lamellas, bands, and layers is a result of aggregation or agglomeration of smaller nano-structures to form larger objects.

\section{Nanostructure, Accessibility and Reactivity of Cellulose}

Due to their developed specific surface, the nano-scale constituents are characterized by increased accessibility (Fig. 8). Investigations of cellulose have shown that smaller crystallites have higher accessibility, solubility, and reactivity (Ioelovich and Gordeev 1994; Ioelovich and Larina 1999). This phenomenon can be explained on the basis of the following equation:

$$
R=R o+k / L
$$

where $R$ and $R o$ are the thermodynamic reactivity of nano-crystallites and large crystals, respectively, $L$ is the lateral size, and $k$ is a coefficient.

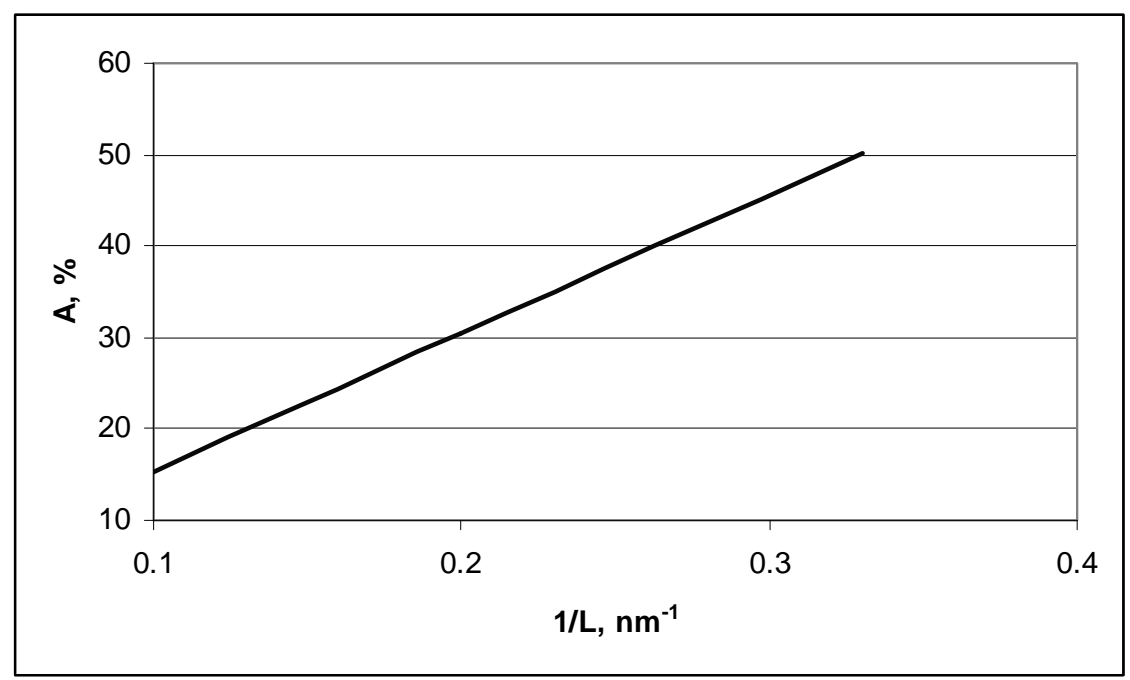

Figure 8. Dependence of the accessibility of cellulose nano-crystallites relative to deuteration on its lateral size

From the relationship (2) it follows that the thermodynamic reactivity of nanocrystallites of chemically pure celluloses to alkalization and xanthation increases with decreasing of lateral size of the crystallites (Fig. 9).

Reactivity of cellulose nano-particles to oxidation also has been studied. After periodate oxidation, the small nanospheres having average diameter of $80 \mathrm{~nm}$ showed higher content of carbonyl groups in comparison to nanospheres with diameter of $360 \mathrm{~nm}$ or nano-whiskers (Zhang et al. 2008). TEMPO-oxidized nano-whiskers exhibited behaviors of liquid crystals and remained non-flocculated in water dispersions (Habibi et al. 2006). The esterification process of nanocellulose and properties of the nanoderivatives were studied by Ifuku at al. (2007). 


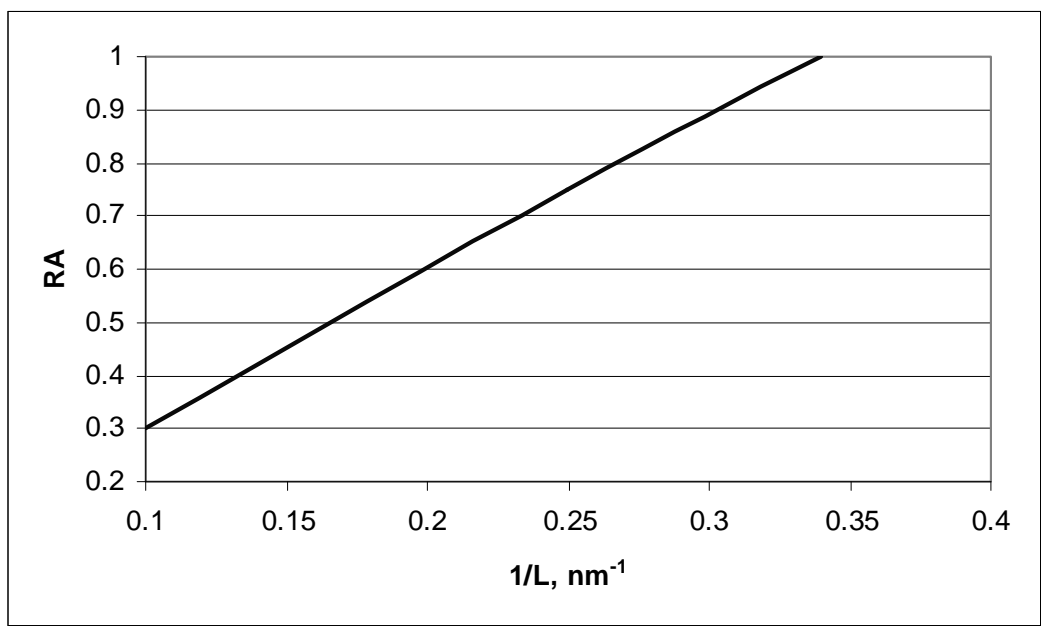

Figure 9. Dependence of relative reactivity of cellulose nanocrystallites toward alkalization on their lateral size

\section{Nanostructure and Temperature Phase Transitions}

As is known, the melting point of large, pure crystals is constant. However, with decreasing crystal size to nano-scale, the melting point will be function on crystal size (L):

$$
T_{n} / T_{o}=1-4 \sigma V_{m} / Q L
$$

where $T_{n}$ and $T_{o}$ are the melting point of nanocrystallites and large crystals, respectively; $Q$ is the heat (enthalpy) of the phase transition; $V$ is the specific molar volume of the crystalline phase; and $\sigma$ is the specific surface energy.

Experimental investigations of Ioelovich and Luksa (1990) concerning melting point of cellulose nanocrystallites with various lateral sizes (Fig. 10) have confirmed the thermodynamical equation (3).

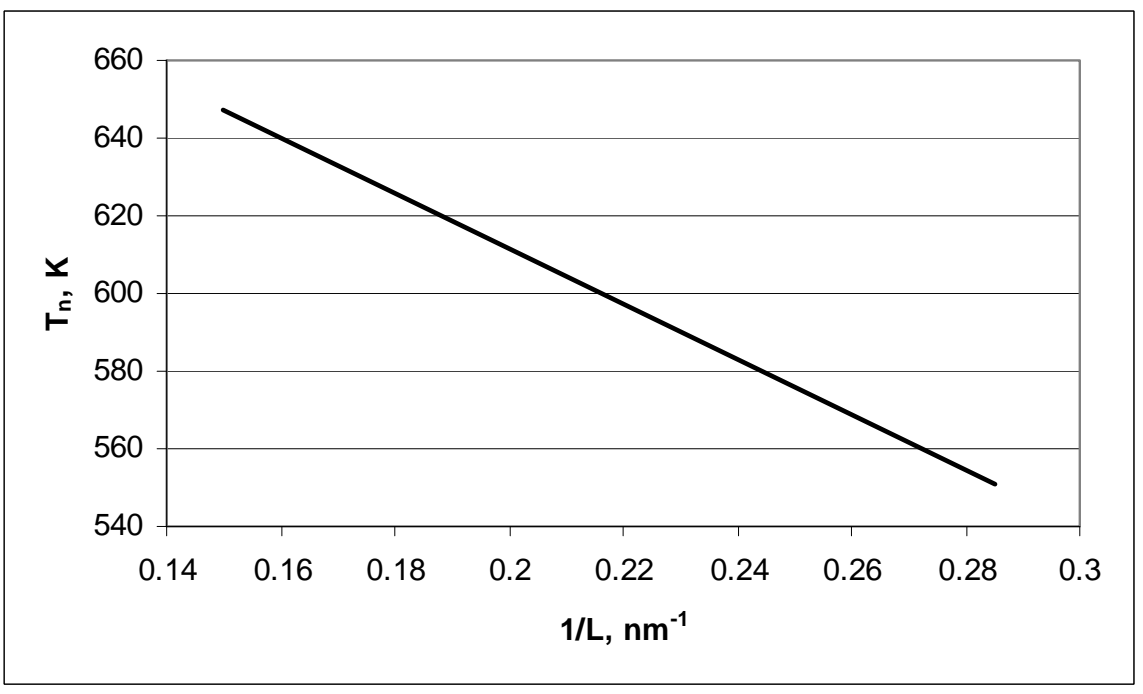

Figure 10. Dependence of melting point on lateral size of cellulose nanocrystallites 


\section{Nanostructure and Rheology of Dispersions}

The peculiarity of cellulose nanoparticles is that their dispersions have unusual rheological properties (Ioelovich and Leykin 2006a). Nanocellulose particles are capable of immobilizing a high amount of water into developed external and internal surfaces with the formation of highly viscous gel-like water systems.

As it follows from experiments, the viscosity of water dispersions containing nanocellulose particles - NC $(20 \times 200 \mathrm{~nm})$ is considerably higher than the viscosity of dispersions containing both small micro - SM (2-3 $\mu \mathrm{m})$ and large micro - LM (10-20 $\mu \mathrm{m})$ cellulose particles (Fig. 11).

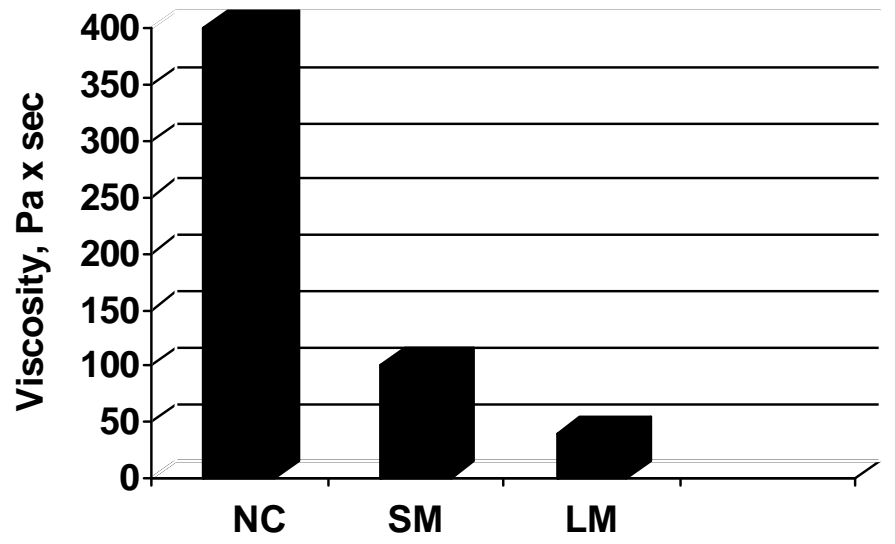

Figure 11. Viscosity of $10 \%$ water dispersions of nano- and micro-cellulose particles at the shear rate of $1 \mathrm{~s}^{-1}$

These results can be explained by means of the modified Einstein equation:

$$
\log \eta / \eta_{o}=\alpha\left(\varphi_{c}+S A\right)
$$

where $\varphi_{\mathrm{c}}$ - volume fraction of cellulose particles;

$\mathrm{S}$ - total specific surface of the water-swollen particles

A - specific water absorption

$\alpha-$ coefficient.

As follows from the eq. (4), at the same $\varphi_{\mathrm{c}}$-value (particle concentration $=$ const), the high specific surface of swollen nano-particles causes a sharp increasing of the viscosity of the dispersion.

\section{Nanostructure of Cellulose and Papermaking}

The majority of commercially harvested cellulose, about 100 million tons per year, is used for production paper and paperboard. The papermaking process includes steps of preparing the paper components, wet beating, forming of the wet sheet, pressing, drying, calendaring, and finishing. Beating or refining of cellulose fibers in water 
medium is the obligatory step of papermaking required to obtain strong paper. Despite the fact that the process of paper forming has been studied for many years, certain substantial problems have not been solved. In recent years the papermaking process has been investigated deeply and in detail, owing to progress in the techniques and methods of nano-structural investigations (improved electron microscopy, atom-force microscopy, X-ray, electron-diffraction, NMR, etc.). Hydrogen bonds play a major role in forming of the interfiber paper contacts. In order to achieve the interfiber hydrogen bonds, direct contacts between fibers should be provided.

However, roughness of the cellulose fibers hinders the formation of direct contacts. Due to fiber roughness the distance between fiber surfaces is some tens of nanometers, which is much more than distance of $0.27-0.3 \mathrm{~nm}$ that is required for forming of the direct hydrogen bonds (Hubbe 2006). To realize the direct interfiber contacts, the cellulose fibers should be preliminary fibrillated by intensive milling (beating) in water medium. The essence of the fibrillation process is splitting off of nanofibrillar bundles from the fiber surface (Fig. 11). Sufficiently long nanofibrils fill the inter-fiber gaps that permit formation of direct contacts through strong hydrogen bonds. Thus, forming nanofibrillar bundles during the cellulose fiber beating process and following their constriction during drying of the wet sheet is an obligatory requirement for obtaining the dense characteristic texture of many kinds of paper.

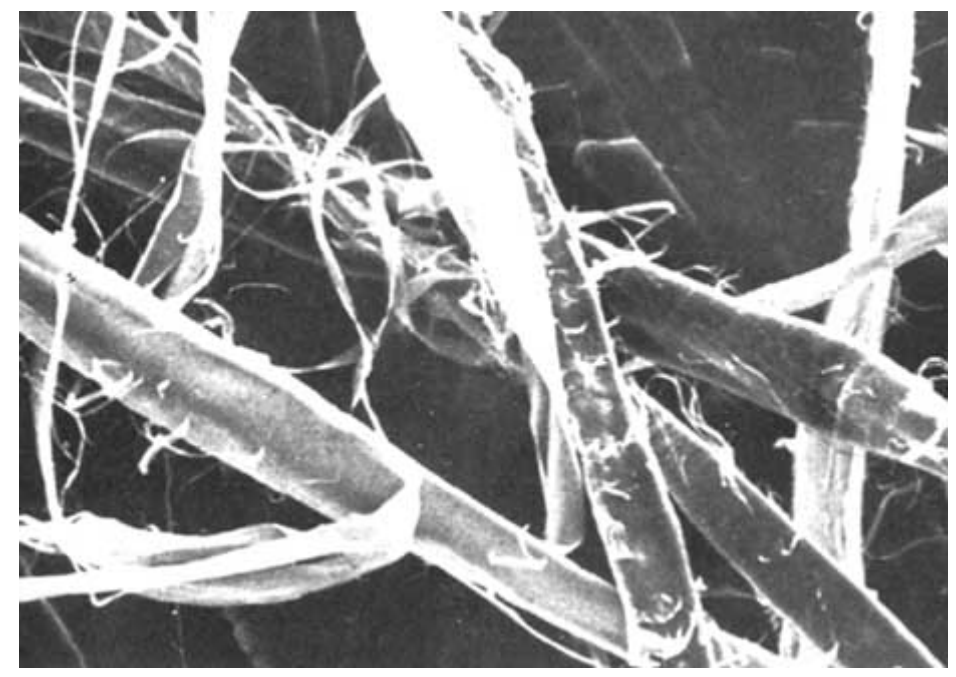

Figure 11. Fibrillated surface of cellulose fibers

Recent developments (Ioelovich and Leykin 2004; Ankerfors and Lindström 2007) have shown the possibility to increase paper strength with additive of nanocellulose particles or nanofibrillated cellulose to paper compositions. Henriksson et al (2008) reported the formation of very dense nano-papers (density $1-1.2 \mathrm{~g} / \mathrm{cm}^{3}$ ) from the dispersion of nanofibrillated cellulose. Such sheets can have excellent mechanical properties, namely Young modulus 10-14 GPa and Tensile strength 130-214 MPa. These characteristics are like that of regenerated cellulose films (cellophane) and 2-5 times higher than that of common papers formed after conventional beating processes. 


\section{Nanocellulose Use to Prepare Polymer Composites}

Nano-cellulose can be used as a reinforcing filler to prepare composites with solutions of water-soluble polymers, as well as with acrylic and other latex to change the viscosity and increase mechanical properties of dry composites. Of great importance has been the addition of nano-cellulose to biodegradable polymers, permitting both the improvement of mechanical properties and acceleration in the rate of biodegradation (Ioelovich and Leykin 2004). Detailed information about nanocellulosic composites with improved mechanical and other properties can be found in reviews of Hubbe et al. (2008) and Azizi Samir et al. (2005), as well as in many articles (Azizi Samir et al. 2004; Chauve et al. 2005; Favier et al. 2005, 2005a; Dalmas et al. 2006; Millon and Wan 2006; Oksman et al. 2006; Heriksson and Berglund 2007a; Cao et al. 2008; Dufresne 2008; etc.).

\section{Nanocellulose Use in Biomedicine and Cosmetics}

Pure nanocellulose is harmless for people and it is biocompatible. Therefore, it can be used for health care applications, such as personal hygiene products, cosmetics, and biomedicine. One of the simplest applications of nanocellulose dispersions is its use for stabilization of medical suspensions against phase separation and sedimentation of heavy ingredients. Chemically modified cellulose can be a promising carrier for immobilization of enzymes and other drugs (Ioelovich and Figovsky 2008a, b). Due to its nano size, such a carrier-drug complex can penetrate through skin pores and treat skin diseases. Moreover, it can be used as a gentle, but active peeling agent in cosmetics.

Nanostructured bacterial cellulose (BC) having a high hydration degree $(99 \%$ water) is applicable in cosmetics as a moistening mask, as well as an ingredient of moistening cream (Klemm et al. 2005; Klemm et al. 2006). BC can be used also in biomedicine for preparation nano-implantates, bandages, tissues, hydogels and some other materials (Klemm et al. 2006; Brown et at. 2007; Hubbe et al. 2008).

\section{CLOSING REMARKS}

Natural and isolated celluloses of various origins have strongly pronounced nanoarchitecture. This architecture comprises nano-crystallites and disordered nano-domains forming the anisometric elementary (primary) nano-fibrils with lateral size of 3-15 nm; secondary aggregates of the primary nano-fibrils, i.e. nano-bundles with lateral size of 20-40 nm; agglomerates of the secondary nano-bundles, i.e. lamellas, bands and layers with lateral size of 100-200 $\mathrm{nm}$. The nano-structured architecture of cellulose promotes isolation of nano-particles and nano-fibrils from initial fibers by various methods that facilitate breaking up of the glycoside bonds in the disordered nano-domains of nanofibrils and cleaving of inter-fibrillar contacts.

To explain the structure-property relationships of nanostructured cellulose, thermodynamical and physico-chemical laws for transformations of small phases have been taken into consideration. These laws permit interpretation of such phenomena as distortions and accessibility of nanocrystallites, and also the effects of aggregation, 
dissolution, reactivity, and thermal transitions of nanostructured celluloses and nanocelluloses.

The nanostructure of cellulose can play a significant part in papermaking and manufacture of high-quality nano-composites, as well as in technology of promising health care nano-products. It seems that among various applications, use of nanocellulose and its derivatives in health care areas will be especially promising due to their biocompatibility and some other unique properties.

\section{REFERENCES CITED}

Ander, P., Hilden, L., and Daniel, G. (2008). "Cleavage of softwood kraft pulp fibers by $\mathrm{HCl}$ and cellulases," BioResources 3(2), 477-490.

Azizi Samir, M. A. S., Alloin, F., Sanchez, J. Y., and Dufresne, A. (2004). "Cellulose nanocrystals reinforced poly(oxyethylene)," Polymer 45(12), 4149-4157.

Azizi Samir, M. A. S., Alloin, F., and Dufresne, A. (2005). "Review of recent research into cellulosic whiskers, their properties and their application in nanocomposite field," Biomacromolecules 6, 612-626.

Brown, R., Czaja, W., Jeschke, M., and Young, D. (2007). "Multi-ribbon nanocellulose as a matrix foe wound healing," US Pat. 2007053960.

Bhatnagar, A., and Sain, M. (2003). "Manufacturing of nano-fibrils," Can. Patent 02437616.

Bhatnagar, A., and Sain, M. (2005). "Processing of cellulose nanofiber-reinforced composites," J. Reinforced Plastic Composites 24(12), 1259-1268.

Cao, X., Chen, Y., Chang, P. R., Muir, A. D., and Falk, D. (2008). "Starch-based nanocomposites reinforced with flax cellulose nanocrystals," XPRESS Polymer Letters 2(7), 502-510.

Cavaille, J. Y, Chanzy, H., Favier, V., and Ernst, B. (2000). "Cellulose microfibril-reinforced polymers and their applications." US Patent 6103790.

Chakraborty, A., Sain, M., and Kortschot, M. (2005). "Cellulose microfibrils: A novel method of preparation using high-shear refining and cryocrushing." Holzforschung 59(1), 102-107.

Chauve, G., Heux, L., Arouini, R., and Mazeau, K. (2005). 'Cellulose poly(ethylene-covinyl acetate) nanocomposites studied by molecular modeling and mechanical spectroscopy," Biomacromolecules 6(4), 2025-2031.

Dalmas, F., Chazeau, L., Gauthier, C., Cavaille, J.Y., and Dendievel, R. (2006). "Large deformation mechanical behavior of flexible nanofiber filled polymer nanocomposites," Polymer 47(8), 2802-2812.

Dufresne, A. (2008). "Polysaccharide nano crystal reinforced nanocomposites," Can. J. Chem. 86(6), 484-494.

Favier, V., Chanzy, H., and Cavaille, J. Y. (1995). "Polymer nanocomposites reinforced by cellulose whiskers," Macromolecules 28(18), 6365-6387.

Favier, V., Canova, G. R., Cavaille, J. Y., Chanzy, H., Dufresne, A., and Gauthier, C. (1995a). "Nanocomposite materials from latex and cellulose whiskers," Popymers Advan. Technol. 6(5), 351-355. 
Fink, H-P., Purz, H., Bohn, A., and Kunze, J. (1997). "Structural investigations of bacterial cellulose," Macromol. Symp. 120, 207-217.

Frolov, Yu. (1982). Colloidal Chemistry - Surface Effects and Disperse Systems, Science, Moscow.

Habibi, Y., Chanzy, H., and Vigon, M. (2006). "TEMPO-mediated surface oxidation of cellulose whiskers," Cellulose 13, 679-687.

Henriksson, M., Henriksson, G., Berglund, L. A, and Lindstrőm, T. (2007). “An environmentally friendly method for enzyme-assisted preparation of microfibrillated cellulose nanofibers," Eur. Polymer J. 43(8), 3434-3441.

Henriksson, M., and Berglund, L. A. (2007a). "Structure and properties of cellulose nanocomposite film containing melamine formaldehyde," J. Appl. Polymer Sci. 106(4), 2817-2824.

Henriksson, M., Berglund, L.A, Isaksson, P., Lindstrőm, T., and Nishino, T. (2008). "Cellulose nano-paper structures and high toughness," Biomoleculares 9, 1579-1585.

Hubbe, M. A. (2006). "Bonding between cellulosic fibers in the absence and presence of dry-strength agents - A review," BioResources 1(2), 281-318.

Hubbe, M. A., Rojas, O. J., Lucia, L. A., and Sain, M. (2008). "Cellulosic nanocomposites - A review." BioResources 3(3), 929-980.

Ioelovich, M., and Ivulonok, Z. (1987). "Study of structure-strength relationship for cellulose fibers and films," Wood Chemistry 4, 3-8.

Ioelovich, M., Treimanis, A., Klevinska, V., and Veveris, G. (1989). "Changes of cellulose crystalline structure during its isolation from wood," Wood Chemistry 5, 10-13.

Ioelovich, M., and Luksa, R. (1990). "Changes of cellulose crystalline structure during thermal treatment," Wood Chemistry 3, 18-20.

Ioelovich, M., and Leykin, A. (2004). "Nano-cellulose and its application," J. SITA 6(3), 17-24.

Ioelovich, M. (1991). "Study of cellulose cocrystallization process during its isolation from plants," Wood Chemistry 4, 27-33.

Ioelovich, M. (1992). "For supermolecular structure of native and isolated celluloses," Acta Polymerica 43, 110-113.

Ioelovich, M., and Gorgeev, M. (1994). "Crystallinity of cellulose and its accessibility during deuteration," Acta Polymerica 45, 121-123.

Ioelovich, M. (1999). "Concept of the native cellulose structural organization," J. SITA 1(1), 68-77.

Ioelovich, M., and Larina , E. (1999). "Parameters of crystalline structure and their influence on the reactivity of C1," Cellulose Chem. Technol. 33, 3-12.

Ioelovich, M., and Leykin, A. (2006). "Microcrystalline cellulose: Nano-structure formation," Cellulose Chem. Technol. 40(5), 313-317.

Ioelovich, M., and Leykin, A. (2006a). "Structural characteristics and rheological properties of MCC," Cellulose Chem. Technol. 40(9), 699-702.

Ioelovich, M., and Leykin, A. (2008). "Structural investigations of various cotton fibers and cotton celluloses," BioResources 3 (1), 170-17).

Ioelovich, M., and Figovsky, O. (2008 a). "Nano-cellulose as promising biocarrier," J. Adv. Materials Res. 47-50, 1286-1289. 
Ioelovich, M., and Figovsky, O. (2008 b). "Nano-cellulose as a biocarrier." J. SITA 10(1), 37-41.

Ifuku, S., Nagi, M., Abe, K., Handa, K., Nakatsubo, F., and Yano, H. (2007). "Surface modification of bacterial cellulose nanofibers for property enhancement of optically transparent composites: Dependence on acetyl-group DS," Biomacromolecules 8(6), 1973-1979.

Katkevich, Yu, and Milutina, S. (1972). Wood Cell Wall and its Change under Chemical Treatments, Zinatne, Riga.

Klemm, D., Heublein, B., Fink, H-P., and Bohm A. (2005). "Cellulose: Fascinating biopolymer and sustainable raw material," Angewandte Chemie 44, 2-37.

Klemm, D., Schumann, D., Kramer, F., Hessler, N., Hornung, M., Schmauder, H-P., and Marsch, S. (2006). "Nanocelluloses as innovative polymers in research and application," Adv. Polymer Sci. 205, 49-96.

Larsson, T. (2007). Characterization of the Fine Structure and Properties of Papermaking Fibres using New Technologies, Zinatne, Riga.

Li, X.-F., Ding, E.-Y., and Li, G.-K. (2001). "A method of preparing spherical nano-crystal cellulose with mixed crystalline forms of cellulose I and II," Chinese Journal of Polymer Sci. 19(3), 291-296.

Lima, M. M. D., and Borsali, R. (2004). "Rod-like cellulose microcrystals: Structure, properties and applications," Macromol. Rapid Comm. 25(7), 771-787.

Millon, L. E., and Wan, W. K. (2006). "The polyvinyl alcohol-bacterial cellulose system as a new nanocomposite for biomedical applications," J. Biomed. Matter. Res. Part B - Appl. Biomater. 79B(2), 245-253.

Moran, J. I., Alvarez, V. A., Cyras, V. P., and Vazquez, A. (2008). "Extraction of cellulose and preparation of nanocellulose from sisal fibers," Cellulose 15(1), 149159.

Nakagaito, A. N., and Yano, H. (2004). "The effect of morphological changes from pulp fibers towards nano-scale fibrillated cellulose on the mechanical properties of highstrength plant fiber based composites," Appl. Phys. A-Mater. Sci. Proc. 78(4), 547552.

Nieduszynski, I., and Preston, R.D. (1970). "Crystallite size in natural cellulose," Nature 225(17), 273-275.

Oksman, K., Mathew, A. P., Bondesone, D., and Kvien, I. (2006). "Manufacturing process of cellulose whiskers/polylactic acid nanocomposites," Composites Sci. Technol. 66(15), 2776-2784.

Ono, H., Shimaya, Y., Hongo, T, and Yamane, Ch. (2001). "New aqueous dispersion of cellulose sub-micron particles: Preparation and properties of transparent cellulose hydro-gel," J. Trans. Mater. Res. Soc. of Japan 26(2), 569-572.

Pakko, M., Ankerfors, M., Kosonen, H., Nykanen, A., Ahola, S., Österberg, M., Ruokolainen, J., Laine, J., Larssen, P. T., Ikkola, O., and Lindstrőm, T. (2007). "Enzymatic hydrolysis combined with mechanical shearing and high-pressure homogenization for nanoscale cellulosic fibers and strong gels," Biomacromol. 8(6), 1934-1941.

Preston, R. D. (1975). "X-ray analysis and structure of the components of plant cell wall," Physics Reports 21, 183-226. 
Salmon, S., and Hudson, S. M. (1997). "Crystal morphology, biosynthesis and physical assembly of cellulose, chitin and chitosan,” Polymer Reviews 37, 199-276.

Sarko, A., and Muggli, R. (1974). "Packing analysis of carbohydrates and polysaccharides. Valonia cellulose and cellulose II," Macromolecules 7, 486-494.

Sugiyama, J., Vuong, R., and Chanzy, H. (1991). "Electron diffraction study of the two crystalline phases occurring in native cellulose from an algae cell wall," Macromolecules 24, 4168-4175.

Usmanov, H., and Razikov, K. (1974). Light and Electron Spectroscopy of Structural Transformations of Cotton Fibers, Fan, Tashkent.

Van der Hart, D., and Atalla, R. (1984). "Studies of microstructure in native celluloses using solid-state ${ }^{13}$ C NMR," Macromolecules 17, 1465-1472.

Wada, M., Sugiyama, J., and Okano, T. (1993). "Native celluloses on the basis of two crystalline phase $\left(\mathrm{I}_{\alpha} / \mathrm{I}_{\beta}\right)$ system," J. Appl. Polymer Sci. 49, 1491-1496.

Woodcock, C., and Sarko, A. (1980). "Packing analysis of carbohydrates and polysaccharides. Molecular and crystal structure of native ramie cellulose," Macromolecules 13, 1183-1187.

Zhang, J., Jiang, N., Dang, Zh., Elder, Th., and Ragauskas, A. (2008). “Oxidation and sulfonation of cellulosics," Cellulose 15, 489-496.

Article submitted: August 25, 2008; Peer review completed: Oct. 21, 2008; Revised version received and accepted: Oct. 23, 2008; Published: Oct. 30, 2008. 